\title{
The Ways of Overcoming Misunderstanding in Intercultural Communication: An Overview on the Case of China and Mali
}

Abdoulaye M'Begniga, Muhammad Asif*

$\mathrm{PhD}$ Candidate, School of Journalism and Communication, Anhui Normal University, Wuhu China

\author{
DOI: $\underline{10.36348 / \text { sijll.2020.v03i09.002 }}$ | Received: $09.09 .2020 \mid$ Accepted: 17.09 .2020 | Published: 19.09 .2020 \\ *Corresponding author: Muhammad Asif
}

Abstract

This article examines with some interest the essence of the phenomenon of intercultural communication -the interaction of man in the context of different cultures. It focuses on intercultural communication in perspective of two countries, China and Mali. In fact, in the current context of a world crossed by globalization and the development of the means of communication, individuals are constantly brought to meet people from different cultures.

Keywords: Intercultural communication, interaction, identity, tolerance.

Copyright @ 2020: This is an open-access article distributed under the terms of the Creative Commons Attribution license which permits unrestricted use, distribution, and reproduction in any medium for non-commercial use (NonCommercial, or CC-BY-NC) provided the original author and source are credited.

\section{INTRODUCTION}

In the current context of a world crossed by globalization and the development of the means of communication, individuals are constantly brought to meet people from different cultures [1]. Thus, the basic stages of communication are the formulation of the intention to convey a message, its composition (writing it), the encoding of the message and the transmission of the signal which refers to the reception of it by the recipient who makes an effort to decode and interpret it so that they can fully understand the content of the message. Intercultural communication is the study of interpersonal communication between individuals of different cultures. This is more precisely a transactional, symbolic process involving the attribution of meaning between people of different culture [2]. In fact, Intercultural communication is a historically cultural phenomenon: accompanying the development of the human being, it also constitutes a way of life. According to what cultural anthropologists say, the cultural resemblance of each nation could be explained in large part, if not in full, by the communication or "borrowing" that has happened in history through contact. Otherwise, culture comes from a common origin.

F. Graebner, a German cultural anthropologist, thinks that the distance of two cultural zones cannot prevent intercultural communication whether these zones are close or far apart; because there is a mysterious "cultural wave" [3] intercultural communication is the interaction of man in the context of different cultures. If with the German sociologist Georg Simmel introduce the notion of "foreigner", intercultural communication concerns, on a fundamental level, the relationship of the individual with the foreigner. Simmel's observation of the role of the outsider is part of his general thinking about the relationship between individuals. On its own, communication is a fundamental form of social life. Society is made up of communication between individuals. Some form of communication will become relatively stable after a certain time and thus will constitute the cultural and social structure, which will influence the interaction of individuals [4]. In order to be in conformity with the norm of the group and to remain always in communion with it, an individual, by integrating said group, not only has the obligation to part with a certain individuality, but also he must be animated by a certain tolerance, innate or learned, which is a necessary and fundamental element in intercultural encounter and also in social life. Moreover, the development of economic activities and Chinese migratory flows in Africa go hand in hand today with an increased cultural presence. At a first level, the cultural strategies of the Chinese state are manifested through an appropriation of the theme of "soft power". Since the beginning of the 2000 s, in a context marked by the development of social tensions linked to its economic and political influence, the Chinese government has reconsidered the argumentation of its cooperation policies with African countries, emphasizing "Intercultural communication", on forms of circulation of knowledge supposed to mark a break 
with the "cultural domination" implemented by the West [5]. Thus, the increased presence of China in Mali through the strengthening of its financial aid and the multiplication of its investments has generated what we can call "the strengthening of the intercultural communication between the two countries." This presence has grown in particular through the gradual installation of Chinese state-owned companies, but also with the gradual occupation of the Malian market by certain Chinese businesspersons. This phenomenon gives rise to what is called "the intercultural communication" as individuals from the two countries inevitably meet. Therefore, there are some misunderstandings because two cultures meet.

\section{DISCUSSION}

In order to highlight the multi-polarity of the world, it is important to underline the fact that one of the indicators is its conflicts, the clash in terms of culture and civilization. In the Sino-Malian context, this clash in terms of culture and civilization has not only accentuated over the years, but it has been the cause of some misunderstandings as the Chinese meet their Malian counterparts who were born and grew up in a culture totally different from that of China. It is precisely this cultural difference that we are interested in since the locals (Malians) can observe certain differences in the behaviors, actions and reactions of visitors (Chinese). Indeed, there is a need for an allegory, all or part of the usual mechanism of commentary, exegesis, explanation of different cultural phenomena; it can lead to significant cognitive and emotional changes. To a certain extent, cohabitation would be convenient, easy if the locals had learned certain notions in the culture of the visitors. Alternatively, conversely, these have become fully anchored in the local culture, as there is the assumption that they are more interested in it than they are in their lucrative business. Anyway, there remains the need for learning and education in intercultural communication between two different cultures. However, it would be important to underline that learning or education in intercultural communication can be the cause of contradictions with the local cultural identity: there is in particular the fear due to the fear of losing direction in the local socio-cultural space, there is also the possibility of losing one's identity and possibly the loss of the support of the social group to which one belongs. Thus, in an objective, pragmatic and logical way, the process of intercultural learning must be able to take into account the possibility of emergence, or at least, this approach linked to the existence of such contradictions. One of the important and useful methods against the occurrence of such phenomena is the principle of openness and questioning in the framework of the learning process. In line with this logic, students, as part of their research process, must ensure that cognitive and emotional levels of consciousness can be involved [6].
Thus, as mentioned above, intercultural communication training and intercultural learning can be important ways:

\section{Intercultural Communication Training}

In fact, Intercultural communication training (ICT) is the primary application of intercultural communication theory, the study of intercultural interaction at a group level of analysis. The tactical form of ICT uses culture-general (etic) observational categories to contrast one's own to other worldviews and identify cultural differences that matter for coordinating meaning across cultural boundaries (Milton J. Bennett, Ph.D.) [7] He cited the famous book by Edward T Hall who, in his work entitled "The Silent Language" (1959) first used the term "intercultural communication" to describe a focus on coordinating meaning in cross-cultural encounters. Hall's book builds on programs that he and George Trager conducted at the Foreign Service Institute in the early 1950's, where they faced the need to help business and development workers to be more effective in crosscultural situations. In fact, Hall and Trager essentially created a new educational method intercultural communication training (ICT). In the context of the Sino-African case in general, and Sino-Malian in particular, this approach or method is all the more important than necessary in the sense that it can help to overcome misunderstanding in intercultural communications. This approach, method can be incorporated into school and university programs, why not in training centers, especially that of teachers who will then have the pedagogical task of teaching it not only to students, but also and above all to people, such as in the tourist industry. In intercultural communication training, the role of the teacher is very important as the intercultural competence of teachers refers to the appropriate educational supplies, skills and scientific training they must have for intercultural education [8]. On both sides, teachers are trained to the letter in intercultural communication training and they will be able to inculcate suitable notions of it in students and others. In the case of the intercultural meeting between the two countries, China-Mali, would it be possible, necessary to include the said intercultural communication training in the school program of the locals, or to create a special center for this purpose? In any case, in both camps, it is possible that each is animated by a certain pride that prevents him from being able to integrate fully into the culture of the other. Training in intercultural communication can be a primordial, crucial or even necessary element that can not only facilitate the cohabitation between the two cultures, China-Mali, but also can make it possible to overcome certain bad understandings in intercultural communication. 


\section{Intercultural Learning}

It is undeniable that our life is full of differences. Thus, it is pointless or even foolish to attempt to look for these differences. Indeed, they are so numerous that they go unnoticed, every day everywhere. Whether we are ready to accept it or not, to perceive or not this phenomenon as a threat or not, nothing helps: what is certain and certain, we are forced to face it in one way or another [9].

This is why in the Sino-Malian context where two different ones meet; intercultural learning is not only important, but also necessary because it could make it possible to avoid certain misunderstandings that can arise.

One of the realities of modern society is its plurality, its multiplicity. This is both an undeniable and inevitable reality. It is as much to say that men should live with. In their work, Ruth Soemen, Marc Verlot and Stijn Suijs evoke the three strategies, conscious or unconscious that people use. These include, among others, negation, homogenization and interculturalization. Indeed, according to them, the negation is more and more untenable as the multifaceted reality gains ground and affects more the daily existence and the way of life. The second, which is homogenization, consists in reducing social and cultural differences by putting forward an approach, which is the majority approach. The third and last, that of interculturalization, it takes care not to deny, level or push back into the abnormality the existing diversity; on the contrary, it uses it to make human interaction richer and more creative. The second and the last may well fall within the framework of the sub-theme of our research paper which is obviously intercultural learning insofar as homogenization is part of the logic of elimination or reduction of social differences and cultural aspects of the different socio-cultural elements that come together and interculturalization aims to be the unifier to refine the interaction between these different socio-cultural elements. Especially in the context of the meeting of cultures between China and Africa in general and Mali in particular, where two very rich civilizations, face each other. Indeed, on both sides, the two strategies previously mentioned, namely homogenization and inter-culturalization can have impacts play an essential role in the framework of the interaction between socio-cultural elements in the process of the encounter, or at least, intercultural learning. Furthermore, the important elements in this process are obviously the language and the schools or institutes of specialization, such as the Confucius Institute.

The Confucius Institute, which is proliferating in Africa, and of course in Mali, can be considered as a key element in this context where mention is made to the two strategies previously discussed. As the Director General of Hanban Xu Lin evokes, quoted in an article:
"The success of these Institutes also indicates an interest of Africans in Chinese culture. China is increasingly perceived as a land of opportunities. For some young people in Africa, mastering Chinese therefore sometimes appears as a work opportunity or a plus for their career, which testifies to the motivation in Africa for learning this language which is different from those other regions" [10].

However, despite the development of international cooperation in fields, such as culture, the phenomenon of the globalization of culture is accompanied, guided by the fact that people and nations brandish, in objection, their own culture, identity that they say they preserve at all costs. This behavior manifests itself through one of the three strategies that we have previously mentioned, namely the negation of the other's culture, or simply his rejection.

1. The theory of similarities: SimilarityAttraction Theory [11] postulates that the greater the perception of interpersonal similarity to a person, the greater the attraction to that person. Using the "convergence" strategy will make the transmitter more like the receiver and therefore more attractive.

Although the subjects of the two cultures, namely that of China and Mali, behave, act and react differently, there are certain similarities which can facilitate their cohabitation (eating, speaking, the manner of listening etc.) and make it possible to overcome certain misunderstandings that can emerge.

2. Social identity theory: the individual adapts his way of communicating to maintain a positive personal and social identity. Social identity theory therefore explains the motivation for using the divergence strategy. It would result from a desire to highlight the differentiation with the external-group to ensure a positive social identity.

The allusion is made to this theory by posing it in the context of the behavior of the locals where there is this tendency to cling to the social identity to which they belong. However, tolerance is the virtue that can overcome this tendency.

3. Linguistic differences: When the interlocutor cannot understand what the speaker is expressing and wants to express given that the languages used are different, there are bound to be problems. In addition, when the speaker and interlocutor speak the same language or use the same language, there may be discrepancies in that some words used have different meanings in different contexts, countries or cultures. In intercultural communication, linguistic difference has always been an element that tends to pose a certain barrier, a certain obstacle. In the Sino- 
Malian context, mention is made not only to that of the visitor, but also and above all to local languages because the two parties cannot not speak to each other, communicate. Nevertheless, their learning can also be a facilitating factor in terms of cohabitation

4. Stereotypes: Stereotypes involve placing people in predefined gaps based on how we imagine them to be or how we imagine what they should be. In our view, our way of seeing things is a set of characteristics that we assume that all members of a group share. It can be true or false. Nevertheless, stereotypes can lead to false expectations and notions. Without any bias, stereotypes exist in both parties, Chinese and Malian where some have preconceived ideas, received from others without them being realities, truths and vice versa.

Furthermore, there can be a state of anxiety linked to the fact that we are confronted with a cultural panorama, which differs from ours, and we find ourselves in a dilemma, between action and behavior. This can be considered adequate (For example: an African and a Chinese having a business meeting where both are not sure about each other's cultural norms)

One of the main obstacles to intercultural communication is the lack of a shared and preeminent language and culture. Therefore, in order to be able to establish a progressively enlightened understanding, aware of the cultures of others, it would be important or even necessary to resort to the acquisition of knowledge. The desire to have recourse to the mastery of a few languages that are different from ours in order to be on the same level with those of others can prove to be essential. Knowing, even if only a little, about cultures and traditions that are different from our own can be a factor that can help us identify this complicated and exceptional network of influences that have shaped the citizens of each culture.

The modernity which has imposed itself on almost all aspects of our society, socio-economic, cultural and political as well as the politico-cultural diversity of our world seems to call for the urgent establishment of education and training to tolerance and the science of practical pedagogy. Indeed, this, tolerance, can be an important and necessary element that will play a primordial role when there is any misunderstanding in cultural communication. We speak about the fact that the English language is spoken by almost all the countries of the world, it is important to remember that it is an international language, makes it an important element and tool in intercultural communication. It is undeniable that it is an important link, which can well help learners to better train themselves in tolerance that is very capital in cultural encounter, in cultural communication, in cultural dialogue. In the case of China and Mali, given China's dominance, it is clear that Chinese language has taken the lead. In fact, it is undeniable that chinese language can be important link between the individuals of both countries in their communication, cohabitation, exchange etc. On other hand, the local languages can also play a crucial role for the individuals in their cohabitation, exchange etc. In The Decent Society, the philosopher Avishai Margalit [12] imagines what a "decent" and not just society would be: it would be a society whose institutions do not humiliate the people under their authority. i.e. do not reject them out of the "human family" by treating them as if they are not completely human or at least not as much as others, or again, in the words of Taylor [13], by not recognizing in them the quality of human being who "is worth and who can" [14].

On the other hand, the tolerance which is more alluded to was the tolerance of the religions. However, today, the new cultural - or ethnic-cultural - context in which tolerance must be defined primarily concerns groups, communities or peoples. In fact, the membership of an individual in a group is not made according to the voluntary mode of choice, but depends on a given of origin, customs or tradition. In other words, the group tends to become a reality superior to individuals. This is why tolerance now concerns communities that wish to maintain their ways of life, their traditions and their customs in a country where they are in the minority. This may concern very different cases, from the Native American Indian communities of Canada, to the immigrant communities found in most democratic countries... Mention is made to cultural tolerance that we can assimilate to a state of mind that is a tool, a sine-qua-non element to face a misunderstanding in cultural communication. Education and training in this tolerance is more than necessary. "Tolerance is more than sitting idly by or being oblivious to differences between men and women, cultures and beliefs," said Audrey Azoulay, DirectorGeneral of the United Nations Educational Organization, science and culture (UNESCO), but rather "a state of mind, a conscience and an imperative" [15].

There are stages to be taken in order to achieve a tolerant attitude. There are among others:

1. Knowledge of a country's culture

2. Language learning

3. Specialize in another culture

\section{CONCLUSION}

Growing globalization, which rapidly increases contacts between organizations, groups and individuals from different countries and cultures, means that the issue of intercultural communication becomes one of the marks, of the indisputable characteristics of our current world that does not ceases to modernize. Thus, the basic stages of communication are the 
formulation of the intention to convey a message, its composition (writing it), the encoding of the message and the transmission of the signal which refers to the reception of it by the recipient who makes an effort to decode and interpret it so that they can fully understand the content of the message. Intercultural communication that is communication between representatives of different cultures involves both personal contacts between people. Thus, the increased presence of China in Mali through the strengthening of its financial aid and the multiplication of its investments has generated what we can call "the strengthening of the intercultural communication between the two countries." This presence has grown in particular through the gradual installation of Chinese state-owned companies, but also with the gradual occupation of the Malian market by certain Chinese businesspersons. This phenomenon gives rise to what is called "the intercultural communication" as individuals from the two countries inevitably meet. Therefore, there are some misunderstandings because two cultures meet. Furthermore, it is made up of indirect forms of communication. Tolerance that can be assimilated to a state of mind that is a tool, a sine-qua-non element to face a misunderstanding in cultural communication. Education and training in this tolerance is more than necessary.

\section{REFERENCES}

1. Landis, D., Bennett, J., \& Bennett, M. (2012). Handbook of Intercultural Training, Sage Publications, 2004.

2. Gudykunst and Kim, 1992 cited by Licata and Heine 2012

3. Bo Shan, "Intercultural communication: its foundations, the obstacles to its development", Communication and organization [Online], 24 | 2004, posted on March 27, 2012, consulted on April $30 \quad 2019 . \quad$ URL: http://journals.openedition.org/communicationorp oration/2928; DOI: 10.4000 /communication organization. 2928

4. IBIT

5. Espaces de la présence culturelle chinoise en Afrique et reconfigurations sociales locales See the site: http://etudesafricaines.cnrs.fr/atelier/espaces-de-la-presenceculturelle-chinoise-en-afrique-et-reconfigurationssociales-locales/ Accessed on September 11, 2020

6. Tetiana Tarasenko; Luidmyla Kulykova, The ways of overcoming misunderstanding in cross-culture communication, February 2018

7. Milton, J. B. (1959). "The Silent Language".

8. Papachristos, A. V., Meares, T. L., \& Fagan, J. (2007). Attention felons: Evaluating project safe neighborhoods in Chicago. Journal of Empirical Legal Studies, 4(2), 223-272.

9. Siemen, D., Loupatatzis, C., Borecky, J., Gulbins, E., \& Lang, F. (1999). Ca2+-activated K channel of the BK-type in the inner mitochondrial membrane of a human glioma cell line. Biochemical and biophysical research communications, 257(2), 549-554.

10. China at the bedside of education in Africa Posted on January 28, 2014Updated on May 23, 2016

11. Byrne, 1971; cited by Gallois et al., 2005

12. Margalit, A. (1996). The decent society. Cambridge, MA: Harvard University Press. See the website: https://news.un.org/fr/story/2019/11/1056271

13. Taylor, P. M. (1992). War and the media: Propaganda and persuasion in the Gulf War. Manchester University Press.

14. Ricoeur, P. (1990). John Rawls: de l'autonomie morale à la fiction du contrat social. Revue de Métaphysique et de Morale, 95(3), 367-384.

15. Tolerance Day: diversity is a form of wealth, says UNESCO head See the website: https://news.un.org/fr/story/2019/11/1056271 Accessed September 03, 2020. 